\title{
Inserção Urbana no Programa Minha Casa Minha Vida (MCMV): Avaliação do Conjunto Habitacional Coração de Maria no Município de Salvador, Bahia, Brasil
}

\author{
Urban Insertion in the Housing Program Minha Casa Minha \\ Vida (MCMV): Evaluation of the Coração de Maria Residential in \\ Salvador, Bahia, Brasil
}

\section{Andrea Andrade Prudente* y Manoela de Siqueira Leiro**}

Fecha de recepción: 30-04-2017 - Fecha de aceptación: 16-09-2017

Hábitat y Sociedad (ISSN 2173-125X), n. ${ }^{\circ}$ 10, noviembre de 2017, pp. 269-288.

http://dx.doi.org/10.12795/HabitatySociedad.2017.i10.15

\section{Abstract}

The Housing Program Minha Casa Minha Vida (MCMV) developed since 2009 by the Brazilian Federal Government relocated fundamental questions in the study of habitation of social interest, in relation to its effects in the territory and in the lives of the contemplated families. Although it is innovative in the amounts of aids prevision for the Habitation of Social Interest, the program presents some problems related to the urban insertion of its enterprises. With the objective of evaluating the impacts generated by the urban insertion of the buildings in the lives of the residents, this research adopts as a case study the Coração de Maria Residential, located in Salvador city, Bahia. It involved visits to the residences, observation of the surrounding area, and examination of satellite images. In order to analyze how the residents evaluate their new location, they answered to questionnaires in which it was possible to verify a satisfaction with the acquisition of the own house confused with a disappointment related to the urban area in which the buildings are located. These mixed feelings arouse because the area does not give proper conditions of accessing the city center or social and economic opportunities. In this context, the evaluation of the urban insertion of social housing becomes an important theme to the academic research.

\section{Key words}

Public policy, Habitation of social interest, Urban insertion, Right to the city, Socioeconomic impacts

\section{Resumo}

O desenvolvimento do Programa Habitacional Minha Casa Minha Vida (MCMV) pelo governo federal brasileiro, a partir de 2009, recolocou questões fundamentais ao estudo da Habitação de Interesse Social, em relação aos seus efeitos no território e na vida das famílias atendidas. Embora inovador na previsão de grandes montantes de subsídios para a Habitação de Interesse Social, o programa apresenta problemas relativos à inserção urbana de seus empreendimentos. Com o objetivo de avaliar os impactos gerados, pela inserção urbana dos empreendimentos, na vida dos moradores, escolheu-se como estudo de caso o Residencial Coração de Maria, localizado no município de Salvador, Bahia. A pesquisa envolveu visitas ao residencial, observação do entorno imediato e observação de imagens de satélite. Foram aplicados questionários aos moradores para analisar como eles avaliam o seu novo local de moradia. Verificou-se que, embora exista uma satisfação dos beneficiários pelo ganho da casa própria, esse sentimento se confunde com a insatisfação pela baixa qualidade urbanística, que não possibilita condições de acesso à cidade e a oportunidades de desenvolvimento social e econômico por parte dos moradores. É neste sentido que a avaliação sobre a inserção urbana das moradias sociais aparece como tema relevante para a pesquisa acadêmica.

\section{Pallavras Chave}

Políticas públicas; Habitação de interesse social; Inserção urbana; Direito à cidade; Impactos socioeconômicos

\footnotetext{
* Bacharel em Estatística. Professora do Instituto de Matemática e Estatística da Universidade Federal da Bahia, UFBA, Brasil. C.e.: aprudente@ufba.br.

** Pesquisadora do Laboratório de Habitação e Cidade-LabHabitar da Universidade Federal da Bahia, UFBA, Brasil. Professora do curso de graduação em Arquitetura e Urbanismo da Universidade Salvador, UNIFACS, Brasil. C.e.: manoela.leiro@pro.unifacs.br.
} 


\section{Introdução}

No Brasil, a mais importante norma que garante o direito à moradia dos cidadãos é a Constituição Federal, que a partir da Emenda Constitucional $\mathrm{n}^{\circ} 26$ de 2000, incluiu expressamente no conjunto dos direitos sociais listados no artigo $6 .^{\circ}$, a moradia como direito fundamental. A Lei 10257 de 2001, conhecida como Estatuto da Cidade, passou a definir o direito à moradia como parte do direito à cidade, juntamente com o direito à terra urbana, ao saneamento ambiental, ao transporte, à infraestrutura urbana, ao trabalho, ao lazer, etc. Com a aprovação do Estatuto foram regulamentados os artigos da constituição sobre a função social da propriedade e da cidade. As políticas e estratégias habitacionais para a população de baixa renda ficaram legalmente submetidas ao interesse da sociedade e, sobretudo em nível municipal, onde ocorrem os impactos de sua implantação.

O desenvolvimento do Programa Habitacional Minha Casa Minha Vida (MCMV) pelo Governo Federal brasileiro a partir de 2009, recolocou questões fundamentais ao estudo da moradia social, com destaque para seus efeitos no território e na vida das famílias atendidas. $\mathrm{O}$ MCMV atualmente está em sua terceira fase, tendo contratado, até então, a construção de mais de 4 milhões de novas unidades habitacionais no Brasil, no período 2009 a 2015 . O programa MCMV estabelece condições diferenciadas para a produção de empreendimentos e a compra das unidades habitacionais conforme a renda familiar dos beneficiários. ${ }^{1}$ Apesar de destinar grandes montantes de subsídios para a habitação de interesse social (HIS), o programa apresenta, desde o início, uma série de problemas relativos à inserção urbana de seus empreendimentos.

Com os primeiros resultados marcando a paisagem das cidades, começa a ficar claro que os novos empreendimentos estavam situados em áreas periféricas, muitas vezes fora da mancha de urbanização ou nas suas margens, e em localizações que apresentavam deficiências na oferta de equipamentos e de serviços urbanos. Colocou-se em evidência, entre outros, o tema dos transportes e da mobilidade, que se acentuava pela sua localização periférica (Cardoso y Lago, 2015, p. 30).

Nas duas primeiras versões do programa lançadas pelo governo federal, o Município de Salvador contratou através da parceria com o Governo do Estado da Bahia e Prefeitura Municipal de Salvador, mais de 19 mil unidades habitacionais de interesse social, número bastante significativo para um período de cinco anos (2009 a 2015). De acordo com a Superintendência de Habitação da Secretaria Estadual de Desenvolvimento Urbano (SEDUR), Salvador está entre as cinco cidades com o maior número de contratação de unidades para a faixa 1 do programa. Nessa Faixa, as famílias não têm poder de escolha da localização da futura moradia, uma vez que, pelas normas do programa, são selecionadas por sorteio para os empreendimentos produzidos pelas construtoras.

Nesse contexto, o objeto desta pesquisa é o conjunto habitacional de interesse social Residencial Coração de Maria, produzido pelo Programa Minha Casa Minha Vida na cidade de Salvador, Bahia, Brasil. 


\section{Objetivos da pesquisa}

O objetivo da pesquisa é analisar a inserção urbana do conjunto habitacional Coração de Maria, assim como identificar os impactos para os seus moradores. Segundo Ferreira, "a adequada inserção urbana de um empreendimento habitacional é garantida por boa localização na malha urbana, em regiões com infraestrutura instalada e providas de serviços e equipamentos urbanos" (Ferreira, 2012, p. 68). Em outras palavras, "Um empreendimento habitacional bem inserido na cidade é aquele comprometido com processo de urbanização justo e democrático, que garanta qualidade de vida aos moradores e aos demais cidadãos impactados por ele, direta ou indiretamente" (ob. cit., p. 68).

A pesquisa aborda os seguintes aspectos: relações espaciais e características do conjunto habitacional Coração de Maria, a oferta de infraestrutura e a existência de equipamentos públicos, comércio e serviços no seu entorno imediato. Além disso, caracterizou-se o perfil socioeconômico das famílias a partir da composição dos grupos domiciliares, localização, situação fundiária e urbanística da moradia anterior, forma de acesso ao programa, tempo de deslocamentos cotidianos e impactos da mudança no orçamento familiar.

\section{Metodologia}

A metodologia adotada nessa pesquisa tem como referência a metodologia utilizada para a pesquisa "Ferramentas para avaliação da inserção urbana dos empreendimentos do Programa Minha Casa Minha Vida", desenvolvida pelo Laboratório Direito à Cidade e Espaço Público da Faculdade de Arquitetura e Urbanismo da Universidade de São Paulo (LabCidade-FAU/USP) em conjunto com uma rede nacional formada por onze instituições de pesquisa. ${ }^{2}$ A rede desenvolveu uma metodologia comum para analisar os padrões de inserção urbana dos conjuntos do programa, estruturada a partir de três níveis de análise: escala metropolitana/regional, escala municipal e escala local. A escala adotada para fazer a análise nessa pesquisa é a local. Para analisar as relações espaciais e características do conjunto habitacional Coração de Maria, a oferta de infraestrutura e a existência de equipamentos públicos, comércio e serviços no seu entorno imediato, foram realizadas visitas ao local, levantamento de dados e informações em fontes primárias, com base nos contratos para Habitação de Interesse Social do MCMV no município de Salvador. Também foram consultadas fontes secundárias disponibilizadas em sítios eletrônicos de órgãos públicos e observação de imagens de satélite. Para analisar o perfil socioeconômico e os principais problemas e necessidades foram aplicados questionários aos moradores do conjunto Coração de Maria no período de três meses (Setembro, Outubro e Novembro de 2016). As 25 perguntas que compõem o questionário buscaram atender a seguinte matriz de avaliação (Quadro 1):
2 Este projeto foi apresentado à Chamada Pública MCTI/CNPq/MCIDADES N. ${ }^{\circ} 11 / 2012$, integrando uma rede nacional de 11 equipes que também estão pesquisando o PMCMV. Fazem parte da rede as seguintes instituições de pesquisa: LabCidade-FAU/USP; Instituto Pólis; Peabiru; PUC/SP; IAU-São Carlos; IPUUR/ UFRJ; FAU/UFRJ; UFMG; UFRN; UFC; UFPA. 


\begin{tabular}{|c|c|}
\hline Dimensões & Indicadores \\
\hline I. Condições socioeconômicas & 1. Perfil socioeconômico da família \\
\hline \multirow{2}{*}{ II. Direito à cidade e Inserção urbana } & 2. Mobilidade urbana \\
\hline & 3. Acesso à cidade e serviços \\
\hline III. Satisfação e necessidades do morador & $\begin{array}{l}\text { 4. Avaliação dos moradores sobre necessidades, condi- } \\
\text { ções de moradia e relações sociais. }\end{array}$ \\
\hline
\end{tabular}

Quadro 1. Matriz de avaliação do conjunto habitacional Coração de Maria. Fonte: Elaboração própria.
3 O Escritório do Plano Urbanístico da Cidade do Salvador (EPUCS) surgiu em 1943 e foi o primeiro órgão de regulação e controle de uso do solo do município de Salvador.

4 Somente na segunda metade da década de setenta é que um novo esforço de planejamento da cidade vem a ser desencadeado, com a elaboração do PLANDURB-Plano de Desenvolvimento Urbano da Cidade do Salvador
A população alvo da pesquisa foram os 1.800 domicílios (apartamentos) do conjunto habitacional Coração de Maria. Considerando que a população moradora do empreendimento é relativamente homogênea (famílias com faixa de renda entre 0 e 3 salários mínimos) e com a existência do sistema de referências, isto é, a listagem que permite a identificação dos domicílios na população, o plano amostral escolhido para o estudo foi Amostragem Aleatória Simples sem reposição (AASs). Neste plano uma das unidades populacionais (domicílio) é selecionada aleatoriamente, com igual probabilidade a partir do sistema de referências, e a unidade seguinte será selecionada com a unidade anterior sendo retirada da população. Este procedimento é repetido até que todas as unidades amostrais sejam selecionadas. Como o plano escolhido foi o AASs e os parâmetros populacionais a ser estimados são proporções, mas não existiam informações prévias sobre estas proporções na população, o tamanho da amostra foi calculado através da fórmula:

$$
n=\frac{N}{\frac{4(N-1) E^{2}}{z^{2}}+1}
$$

em que $N$ é o tamanho da população, $E$ é o erro máximo admissível na estimação, $z$ é o quantil da distribuição normal padrão correspondente ao nível de confiança. Segundo Bolfarine y Bussab (2005), esta fórmula produz um valor conservativo para $n$. Com base nas considerações anteriores, e admitindo o grau de confiança de $90 \%$ e a margem de erro máxima de $5 \%$, o número mínimo de entrevistas calculado foi de 236 domicílios. A seleção aleatória dos domicílios foi realizada com o auxílio do software estatístico R (versão 3.3.1).

\section{Breve histórico do crescimento urbano de Salvador}

A cidade do Salvador, Capital do estado da Bahia, foi fundada em 1549 e é o terceiro município mais populoso do Brasil, com 2938092 habitantes. Salvador ingressou no século xxi quatro vezes maior, tanto em população quanto em espaço ocupado. A cidade expandiu-se rapidamente incorporando novas áreas para habitação. Mesmo tendo sua origem como cidade planejada nos primórdios da colonização portuguesa e nos dois Planos Diretores realizados nas décadas de 1940 e 1970 - respectivamente o plano do EPUCS ${ }^{3}$ e o PLANDURB ${ }^{4}$ - , grande parte do assentamento urbano de Salvador caracteriza-se por formas espontâneas de apropriação, onde não vigoram as normas urbanísticas e edilícias instituídas pela municipalidade. Especialmente nos últimos cinquenta anos a mancha urbana mais do que duplicou, ao passo que 
foi se agravando o processo de expansão periférica que comprometeu extensivamente grandes parcelas do território municipal, com padrões de uso e ocupação do solo de baixa qualidade urbana (Figura 1).

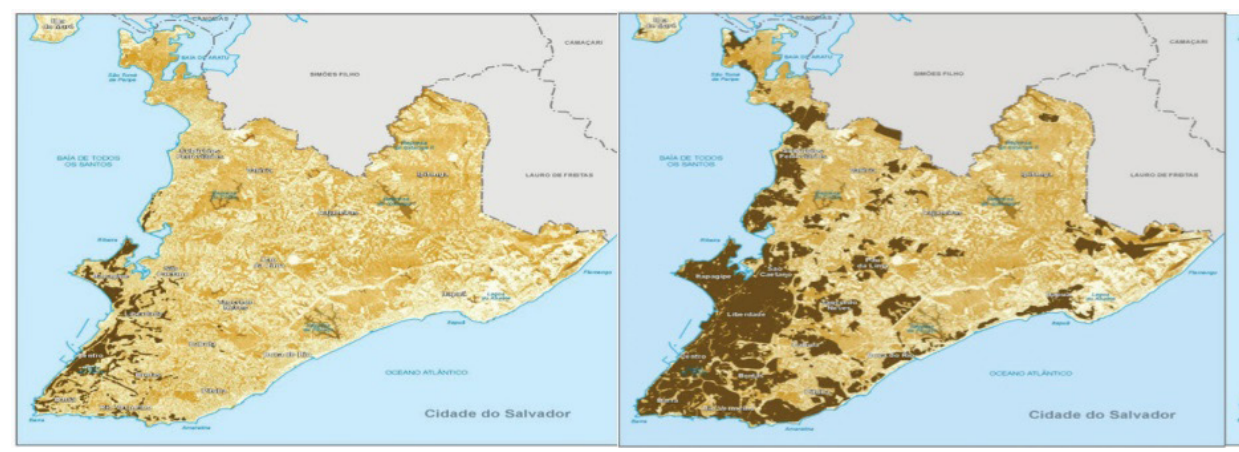

O processo de crescimento e urbanização registrado em Salvador, assim como em outras metrópoles brasileiras, é marcado por uma forte segregação socioespacial que:

constitui, em sua essência, uma questão violenta e desagregadora, e amplia-se como problemática socioespacial e econômica, com a formação do imenso universo da informalidade das ocupações habitacionais, realizadas à revelia dos interesses coletivos, implicando não só a exclusão urbanística de uma grande parcela da população dos direitos de cidadania, como fomentando situações irreversíveis no ambiente construído, que afetam perspectivas de mudanças (Gordilho-Souza, 2008, p. 158).

A cidade de Salvador se expande em diferentes maneiras: a formal, dos bairros organizados com boa oferta de equipamentos e infraestrutura; e a informal, feita pela população mais pobre nas chamadas áreas subnormais (encostas e baixadas) caracterizadas pelas ocupações informais, em decorrência da impossibilidade de acesso ao mercado imobiliário por essa parcela da população. A permanência de um elevado déficit habitacional concentrado na baixa renda evidencia o fracasso dos programas habitacionais públicos e a incapacidade dos mecanismos de mercado para o enfrentamento do problema. Essa situação tem ressaltado a absoluta necessidade de se formular estratégias mais eficazes para atender as faixas de menor poder aquisitivo e o acesso aos bens coletivos da cidade.

\section{O Programa Habitacional Minha Casa Minha Vida (MCMV), 2009}

O Programa MCMV foi criado pela Medida Provisória 459, de 25 de março de 2009, depois convertida na Lei n. ${ }^{\circ} 11977$, de 7 de julho de 2009 , tendo como finalidade criar mecanismos de incentivo à produção e aquisição de novas unidades habitacionais. O programa apresenta condições especificas para diferentes faixas de renda, com valores distintos no que diz respeito aos subsídios, aos mecanismos financeiros e comerciais, bem como o limite de valor das unidades.

Na modalidade "MCMV-Empresas" cabe às empresas construtoras a iniciativa da montagem dos empreendimentos, definindo terreno e quantidade de unidades, dentro das normas gerais do Programa que estabelecem as especificações básicas e os tetos de valores financiáveis.

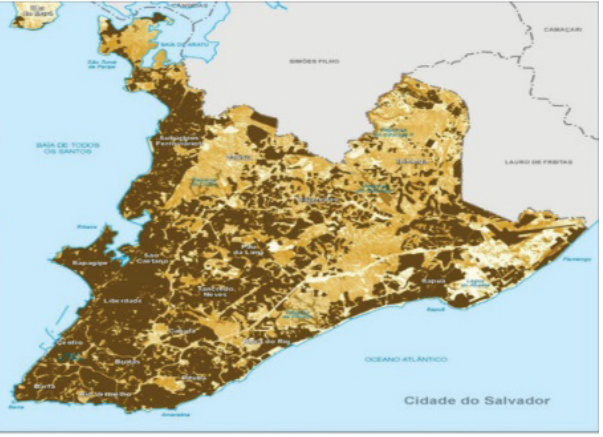

Figura 1. Crescimento urbano de Salvador. Área ocupada nos anos 1940 1976 e 1998. Fonte: Salvador. Evolução demográfica de Salvador $(1940$ 2000). Salvador: UFBA/Centro de Recursos Humanos, 1976. 
Nessa modalidade, na fase atual do programa, são atendidas quatro faixas de renda (Faixas 1, 1,5, 2 e 3). Na primeira, a Faixa 1, o valor do subsídio pode chegar até $90 \%$ do imóvel e os empreendimentos são destinados às famílias com renda mensal bruta de até $\mathrm{R} \$ 1800,00$ (Ministério das Cidades). Os municípios têm como incumbência cadastrar as famílias, além da participação por meio da doação de terrenos, isenção tributária e desburocratização nos processos de aprovação e licenciamento. A forma de acesso ao Programa pelos beneficiários potenciais se dá através da indicação das Prefeituras, a partir de cadastros elaborados com base em critérios de elegibilidade e de priorização. Nessa Faixa,

os moradores são obrigados a pagar uma taxa mensal — que corresponde a 5\% da renda familiar - para a Caixa Econômica Federal, responsável por comprar as unidades da empresa encarregada da construção. A diferença entre o custo da unidade e a quantia total paga pelos moradores é coberta por recursos do Fundo de Arrendamento Residencial (FAR), um fundo público alimentado pelo orçamento federal (Rolnik, 2015, pp. 303-304).

A Faixa 1,5 é destinada às famílias com renda até $R \$ 2600,00$, com taxas de juros de apenas $5 \%$ ao ano e até 30 anos para pagar e subsídios de até 47,5 mil reais (Ministério das Cidades). As Faixas 2 e 3, contam com recursos do Fundo de Garantia de Tempo de Serviço (FGTS). ${ }^{5}$ Nessa situação, a forma de acesso se dá através do mercado: as empresas imobiliárias aprovam seus empreendimentos como Habitação de Interesse Social nas agências locais da Caixa Econômica a partir do seu enquadramento nos critérios mínimos (e máximos) estabelecidos na normativa do Programa. Os empreendimentos podem ter a sua construção financiada pela Caixa ou não, mas o enquadramento é necessário para que os adquirentes possam se beneficiar dos subsídios. As empresas então vendem as unidades aos interessados, que são encaminhados à Caixa para a concessão do financiamento e do subsídio, se for o caso.

No município de Salvador, a Prefeitura realiza inscrição para o Programa desde o início em 2009, tendo mais de 150000 inscritos. Sem dúvida, em Salvador, os últimos anos representam um período significativo de investimentos públicos realizados em habitação social se comparados a períodos anteriores. Para uma análise geral da produção de habitação de baixa renda no período entre 1989 e 1998, Gordilho-Souza (2008), sistematizou resultados por período das gestões municipais de Salvador, informando número de intervenções e unidades habitacionais novas por ano e por período. Para o período de 1989/92 ocorreram 29 intervenções, totalizando uma produção de 3296 unidades habitacionais novas; para o período de 1993/96 ocorreram 19 intervenções, com a produção de 1244 unidades; e no período de 1997/98 ocorreram 65 intervenções e a produção de 8226 unidades habitacionais. Portanto, num período de 10 anos, o número total de unidades novas foi de 12766 .

Nas duas primeiras versões do Programa lançadas pelo governo federal, Salvador contratou, através da parceria com o Governo do Estado da Bahia e Prefeitura Municipal de Salvador, mais de 19 mil unidades habitacionais de interesse social (Vid. Quadro 2), número bastante significativo para um período de cinco anos (2009 a 2015), correspondendo a $57,85 \%$ do total de contratações para todas as faixas de renda no Município. Esse número se compara a capitais brasileiras de grande 
porte como Rio de Janeiro e São Paulo. Segundo a Superintendência de Habitação da Secretaria Estadual de Desenvolvimento Urbano (SEDUR), Salvador está entre as cinco cidades com o maior número de contratação de unidades para a faixa 1 do programa.

\begin{tabular}{|l|l|l|l|l|l|}
\hline Município/UF & Faixa & Contratadas & Valor & Concluídas & Entregues \\
\hline Salvador / BA & Faixa 1 & 19575 & 1026065849 & 15407 & 13071 \\
\hline & Faixa 2 & 5434 & 458982027 & 2916 & 2597 \\
\hline & Faixa 3 & 8826 & 720827220 & 5321 & 2559 \\
\hline Total Salvador/BA & 33835 & 2205875095 & 23644 & 18227 & \\
\hline
\end{tabular}

\section{Estudo de caso: O conjunto habitacional Coração de Maria}

A justificativa pela escolha desse conjunto como estudo de caso está relacionada a algumas das suas características: o empreendimento é um dos maiores construídos pelo MCMV no município de Salvador, com 1.800 unidades habitacionais. A contratação se deu pela modalidade MCMV-Empresas e destinada à Faixa 1, ou seja, a população de menor renda, que pelas próprias regras do Programa não tem o direito da escolha da localização da nova moradia. Vale ressaltar que o conjunto escolhido para análise foi implantado em terreno privado, escolhido pela construtora responsável pela definição do projeto e execução da obra.

\section{Localização}

O Residencial Coração de Maria encontra-se à Estrada das Pedreiras, $\mathrm{s} / \mathrm{n}$, nas proximidades da CEASA-BA (Central de Abastecimento da Bahia), no bairro de Nova Esperança, no município de Salvador, estado da Bahia, Brasil. O empreendimento está situado em área inclusa na poligonal da $\mathrm{APA}^{6}$ (Área de Proteção Ambiental) Joanes-Ipitanga, vizinho ao manancial integrante do sistema de abastecimento da região metropolitana de Salvador. (Figura 2).

O que chama a atenção quando observamos a localização desse empreendimento é que foi implantado no limite extremo norte de Salvador, numa frente de expansão, totalmente fora da malha urbana (Figura 3).

A implantação desse conjunto e a possibilidade de implantação de outros empreendimentos habitacionais nas proximidades do manancial do Ipitanga trazem à tona questões relevantes como os impactos no ecossistema local, assim como à destinação dos resíduos das habitações, do abastecimento de água e do desmatamento da vegetação nativa.

A APA Joanes-Ipitanga, instituída pelo Decreto Estadual n. 7.596, em 05/06/1999, que envolve parte considerável dos municípios de Salvador, Simões Filho, Candeias, São Francisco do Conde, São Sebastião do Passé, Camaçari, Dias D’Ávila e Lauro de Freitas, possui uma área de mais de 600.000ha nas Bacias do Joanes e do Ipitanga, com nascentes, represas e estuários. A cobertura vegetal na referida APA está representada por um mosaico de ecossistemas diversificados, composto por vegetação de restinga, remanescentes de floresta ombrófila e manguezais, todos associados ao bioma Mata Atlântica (Santos et al., 2010, p. 311).
Quadro 2: Contratações MCMV para o município de Salvador, período 2009 a 2015. Fonte: Caixa Econômica Federal 2016
6 Área de Proteção Ambiental (APA)categoria de área, integrante do Sistema Nacional de Unidades de Conservação (SNUC), geralmente extensa, com um certo grau de ocupação humana, dotada de atributos abióticos, bióticos, estéticos ou culturais, especialmente importantes para o desenvolvimento sustentável e o bem estar das populações humanas, e que tem como objetivos básicos proteger a diversidade biológica, disciplinar o processo de ocupação e assegurar a sustentabilidade do uso dos recursos naturais. 


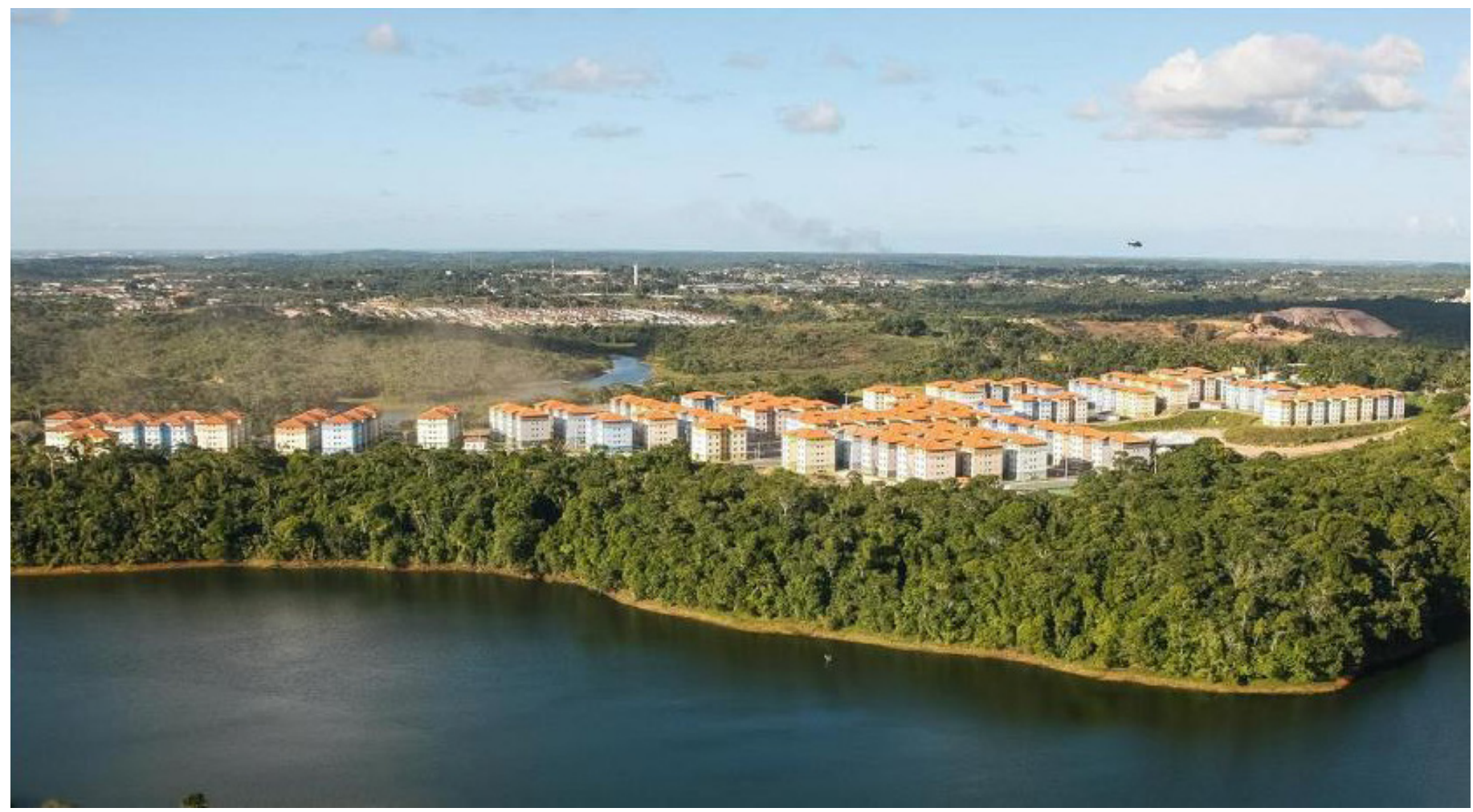

Figura 2. Imagem aérea do Residencial Coração de Maria no município de Salvador. Fonte: Wikimapia, 2016
Por manter ainda uma baixa densidade ao longo das quase três décadas de ocupação, a vegetação nativa ainda não foi dizimada. A área concentra indicadores precários em infraestrutura, além dos piores resultados em saneamento básico e urbanização de Salvador, comparando-se com outras áreas da cidade. (IBGE). Isso se deve ao fato de que somente a partir do PDDU 2008 (Salvador, 2008) essa região passou a ser considerada como zona urbana, atraindo os interesses do setor imobiliário para abrir uma nova frente de expansão.

\section{Perfil socioeconômico dos moradores}

Para iniciar a análise do perfil das famílias do conjunto habitacional Coração de Maria será apresentada a forma de acesso ao domicílio no empreendimento e a situação de propriedade dos imóveis. No universo desta pesquisa, $93,6 \%$ das famílias acessaram ao MCMV através do sorteio do cadastro das Prefeituras, $3,4 \%$ através do reassentamento e $1,7 \%$ acessaram de outra forma. Na categoria "Outra", estão incluídas as famílias que vivem de aluguel, que usam o imóvel emprestado de outra pessoa, ou que tiveram indicação política, entre outras formas.

Para compreender a situação da moradia anterior, o questionário aplicado contou com a análise de quatro questões: local de moradia anterior,

Figura 3. Mapa de localização do empreendimento Coração de Maria no Município de Salvador. Fonte: Elaboração própria com base no mapa Centralidades do PDDU, 2016. 


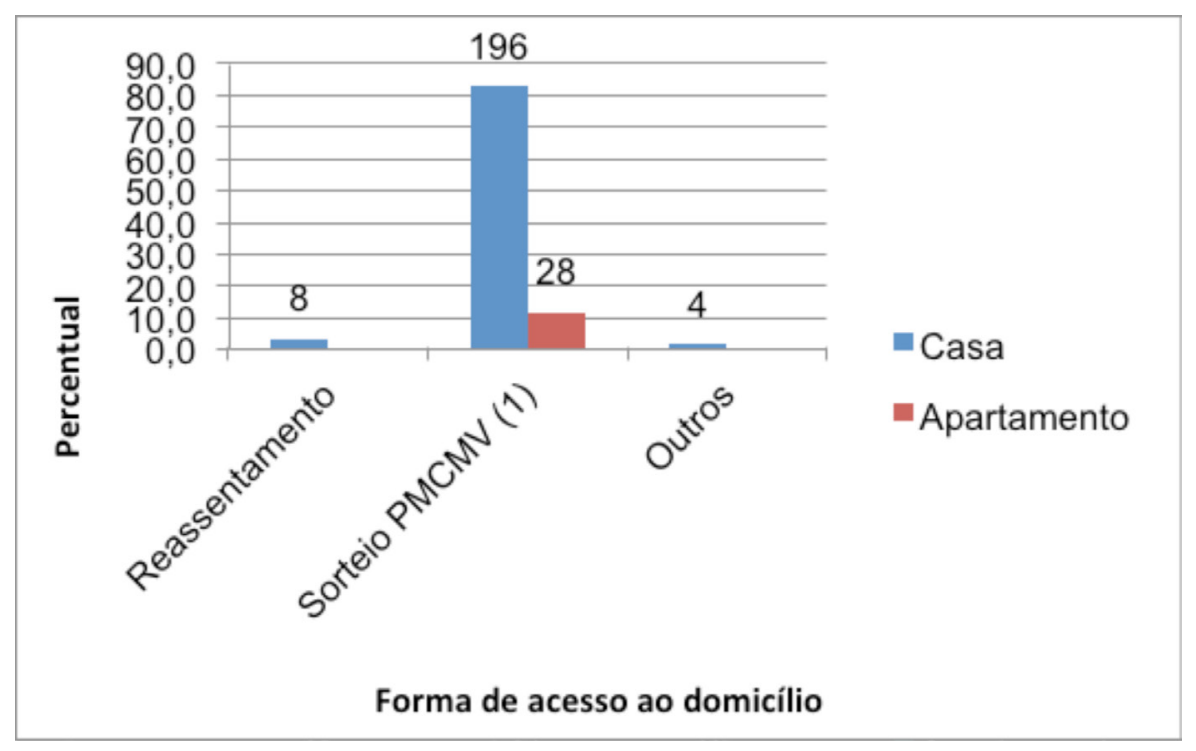

tipo de ocupação da moradia anterior, tipologia da moradia anterior e forma de acesso ao domicílio anterior. Considerando todas as famílias entrevistadas, $27,1 \%$ delas vieram de áreas consolidadas/loteamentos, $44,0 \%$ de comunidades/favelas, $10,2 \%$ de conjuntos habitacionais e 18,7\% de área de risco. Em relação a tipologia da moradia anterior, a maioria das famílias do Residencial Coração de Maria (88,1\%), entre as diferentes formas de acesso ao domicílio, morava anteriormente em casa, ao passo que somente $11,9 \%$ do total vivia em apartamento (Figura 4).

Em relação à posse da moradia anterior, a pesquisa indicou que mais da metade $(51,3 \%)$ dos moradores do empreendimento morava de aluguel. Já em relação à situação da propriedade dos novos imóveis adquiridos pelo Programa MCMV, e como seria de se esperar, 98,7\% das unidades são próprias. Em relação à segurança da posse, o Programa MCMV assegura às famílias, de forma positiva, o título de propriedade privada individual, desde que quitadas todas as parcelas devidas. As entrevistas realizadas demonstraram como os próprios moradores consideram importante essa segurança conferida pelo MCMV. Isso parece estar diretamente relacionado com a situação de insegurança que viviam anteriormente, tendo em vista que mais de $60 \%$ das famílias entrevistadas provinham de favelas e áreas de risco e, muito provavelmente, não tinham seus direitos possessórios formalmente reconhecidos.

\section{Composição das famílias}

Quanto ao número de pessoas por família, no Residencial Coração de Maria as famílias com 2 pessoas $(39,4 \%)$ é quase igual às famílias com 3 a 4 pessoas $(40,7 \%$ ). Em seguida vem as famílias com 5 a 7 pessoas $(10,6 \%)$ e com 1 pessoa $(8,9 \%)$. Apenas $0,4 \%$ dos moradores possuem famílias com mais de 7 pessoas.

\section{Renda}

Em relação à renda, 41,9\% das famílias do Residencial Coração de Maria ganha até 1 salário mínimo (SM). 33,5\% ganha de 1 a 2 salários mínimos e 10,2\% ganha de 2 a 3 salários. Portanto, pode-se dizer que o Programa está conseguindo atingir o público alvo planejado. Apenas 3,8\% das famílias ganha acima de 3 SMs, conforme mostra a Figura 5.
Figura 4. Gráfico do percentual da tipologia de moradia anterior por forma de acesso ao domicílio. Fonte: Elaboração própria baseada nos questionários da pesquisa. 
Figura 5. Gráfico da distribuição, em percentual, das famílias entrevistadas por faixa de renda. $\bigcirc$ valor do salário-mínimo considerado é $R \$ 880,00$, vigente em 2016, período da pesquisa de campo. Fonte: Elaboração própria baseada nos questionários da pesquisa.

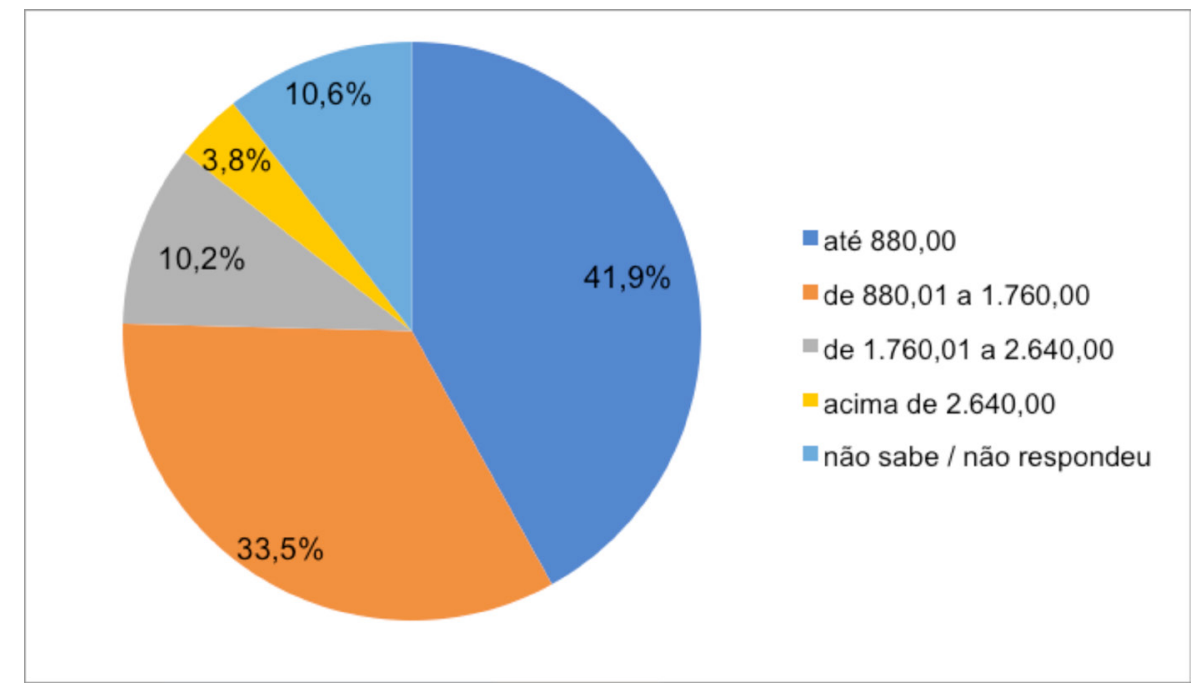

\section{Custo acessível}

Considerando todos os gastos com moradia, ou seja, prestação do financiamento do MCMV, condomínio, água, luz, gás, telefone/internet e TV a cabo, $81,8 \%$ das famílias do Residencial Coração de Maria aumentaram seus gastos. Antes da mudança para o empreendimento em questão, apenas $4,2 \%$ das famílias pagavam condomínio, conforme dados apresentados no Quadro 3.

\begin{tabular}{|l|l|l|l|l|}
\hline Contas & Aumentou & Ficou igual & Diminuiu & Não sabe/Não respondeu \\
\hline Prestação & $223(94,5)$ & - & - & $13(5,5)$ \\
\hline Condomínio & $226(95,8)$ & - & $10(4,2)$ & - \\
\hline Luz & $108(45,8)$ & $15(6,4)$ & $91(38,6)$ & $22(9,3)$ \\
\hline Água & $120(50,8)$ & $13(5,5)$ & $87(36,9)$ & $16(6,8)$ \\
\hline Gás & $99(41,9)$ & $93(39,4)$ & $26(11,0)$ & $18(7,6)$ \\
\hline Telefone/Internet & $36(15,3)$ & $154(65,3)$ & $42(17,8)$ & $4(1,7)$ \\
\hline Tv a cabo & $34(14,4)$ & $183(77,5)$ & $15(6,4)$ & $4(1,7)$ \\
\hline Total de gastos & $193(81,8)$ & $1(0,4)$ & $42(17,8)$ & - \\
\hline
\end{tabular}

Quadro 3. Comparação entre gastos declarados, de todos os domicílios entrevistados, antes e depois da mudança para o empreendimento, em valor absoluto e percentual. Fonte: Elaboração própria baseada nos questionários da pesquisa.
"Tendo em vista que diversos empreendimentos MCMV estão sendo entregues sob a forma de condomínio, as taxas condominiais também passam a fazer parte dos custos associados à moradia" (Rolnik, 2014, p. 408). O peso da prestação não é efetivamente relevante diante dos grupos de renda dos moradores entrevistados, mas quando se adiciona o valor da taxa condominial, o comprometimento médio já dá um primeiro salto, passando para quase $11 \%$ para os que ganham até um salário mínimo. Constata-se, por fim, que o comprometimento da renda fica seriamente preocupante no momento em que são adicionadas as despesas com água, luz e gás, chegando a 33,8\% de comprometimento médio da renda. Segundo Rolnik (ob. cit.), deve ser dada especial atenção nesse ponto aos moradores provenientes de reassentamento, já que muitos deles, ao entrarem na nova moradia, não por opção, passam a ter automaticamente diversos gastos que antes não possuíam de água, luz ou taxas condominiais. 


\section{Disponibilidade de serviços, Infraestrutura e equipamentos públicos}

O empreendimento Coração de Maria foi contratado em meados de 2012 e teve seu início de obra em 27/12/2012, mas a entrega às famílias só ocorreu em abril de 2016. A obra teve como valor investido $R \$ 153.647 .964,75$ milhões e contrapartida do governo estadual de $\mathrm{R} \$ 38.447 .964,75$ milhões. Quando o projeto foi aprovado, não havia qualquer infraestrutura no local e, por isso, a obra se estendeu por um longo período. Durante a execução da obra, a construtora responsável precisou comprar água por meio de carros pipas e os esgotos produzidos foram direcionados para fossas e posteriormente recolhidos por caminhão limpa-fossa. A ampliação do sistema de esgotamento sanitário só foi realizada posteriormente.

Embora no momento da contratação ainda não houvesse infraestrutura disponível no local da implantação, e a implantação dessa infraestrutura tenha implicado em ampliação nos sistemas de esgotamento sanitário e de abastecimento de água do Município, os moradores do Residencial Coração de Maria receberam o empreendimento com a infraestrutura básica: rede de água, esgoto, drenagem, energia elétrica, iluminação pública e pavimentação, conforme mostram as Figuras 6, 7, 8 e 9. [arriba] Figuras 6 e 7. Estação Elevatória da Embasa y Medidores individuais de água. Fonte: acervo próprio.

[abajo] Figuras 8 e 9. Distribuição da rede de iluminação e lluminação pública na rua principal. Fonte: acervo próprio.
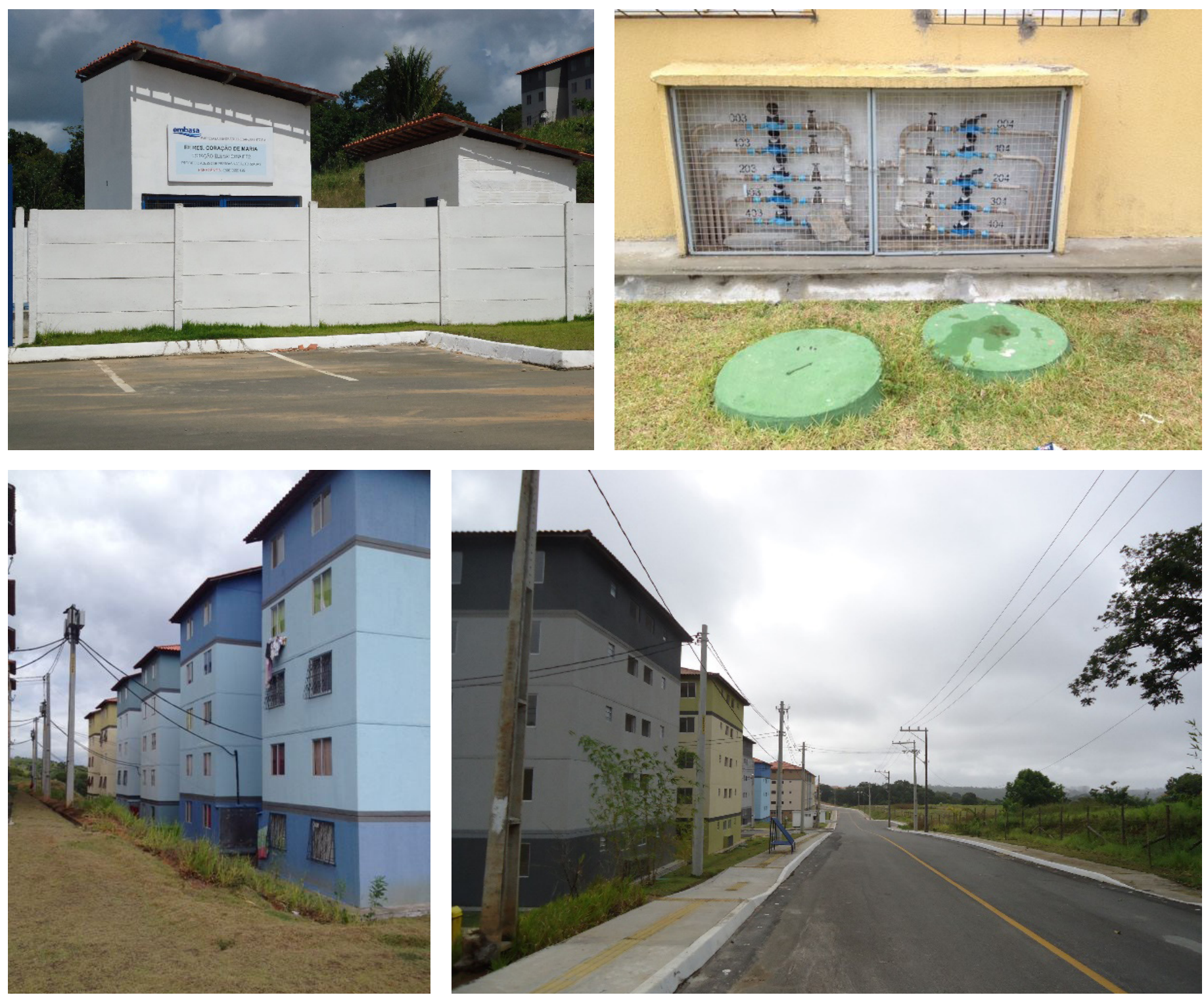


\section{Transporte}

Em relação a oferta de transporte público coletivo, identificou-se os pontos de transporte localizados em um raio de aproximadamente $1 \mathrm{~km}$ do empreendimento, bem como as linhas de transporte que passam pelos pontos. Existem apenas dois pontos de ônibus nas proximidades do Residencial Coração de Maria. As distâncias a serem percorridas a pé são curtas e a proximidade do transporte público é fundamental, mas estar a um quilômetro de um ponto de ônibus não significa garantia de boa acessibilidade urbana. Seria necessária a integração à outras linhas de ônibus ou mesmo a outras modalidades de transporte coletivo (como trem ou metrô). Fato que não acontece no Residencial Coração de Maria que é servido de uma única linha de ônibus: Estação Pirajá-Ceasa Pedreira (C Maria).

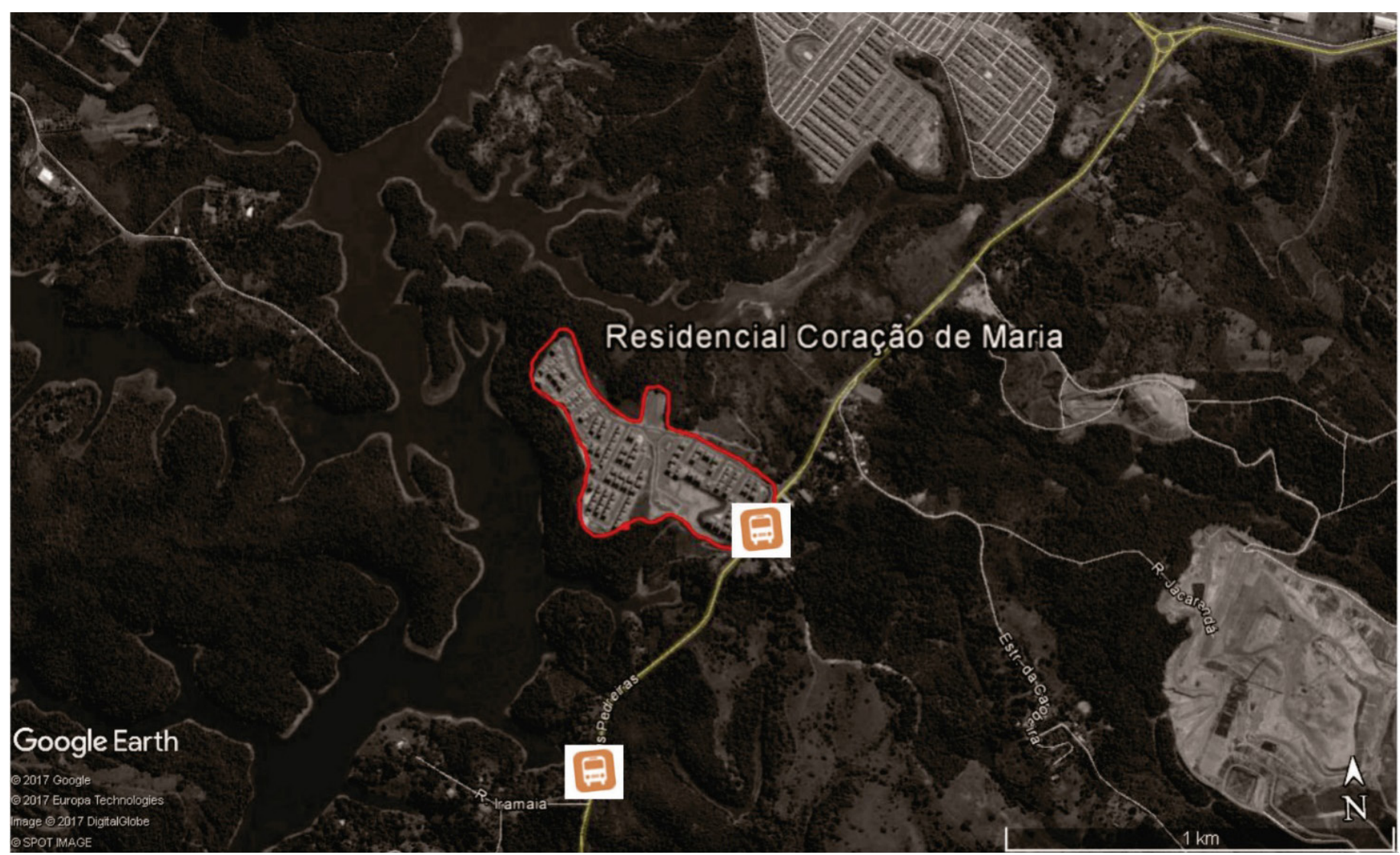

Figura 10. Localização pontos de ônibus no entorno do empreendimento Residencial Coração de Maria. Fonte: Elaboração própria com base em imagem de satélite do Google Earth.
A oferta de uma única linha de ônibus para o Residencial Coração de Maria é insuficiente e prejudica bastante a mobilidade dos seus moradores. Os tempos de deslocamento casa-trabalho-casa, ou casa-outra atividade-casa, apresentaram valores elevados, com cerca de $26,2 \%$ dos entrevistados demorando entre 1 a 2 horas em seus deslocamentos diários para o trabalho e 22,9\% demorando até 3 horas. No caso do deslocamento casa-outra atividade-casa, 26,5\% dos moradores demoram até 4 horas em seus deslocamentos, conforme apresentado no quadro 4. Vale destacar que o Residencial Coração de Maria foi implantado em uma área de expansão do município e está próximo $(2 \mathrm{~km})$ do Residencial Ceasa, outro empreendimento do MCMV, também destinado a famílias enquadradas na Faixa 1, com 1887 unidades habitacionais que, juntos, somam 3687 unidades habitacionais. 


\begin{tabular}{|l|l|l|}
\hline Tempo de deslocamento & Casa-Trabalho_Casa & Casa-Atividade_Casa \\
\hline De 0 a 30 minutos & $1(0,4)$ & $1(1,0)$ \\
\hline De 31 minutos a 1 hora & $14(5,0)$ & $14(13,7)$ \\
\hline De 1 hora e 1 minuto a 2 horas & $73(26,2)$ & $20(19,6)$ \\
\hline De 2 horas e 1 minuto a 3 horas & $64(22,9)$ & $20(19,6)$ \\
\hline De 3 horas e 1 minuto a 4 horas & $33(11,8)$ & $27(26,5)$ \\
\hline Mais que 4 horas & $12(4,3)$ & $13(12,7)$ \\
\hline Não sabe/Não respondeu & $82(29,4)$ & $7(6,9)$ \\
\hline Total & $279(100,0)$ & $102(100,0)$ \\
\hline
\end{tabular}

A mudança da moradia anterior para o MCMV aumentou o tempo de deslocamento entre casa e trabalho para $59,5 \%$ dos moradores, enquanto esse deslocamento diminuiu para apenas 13,5\% dos entrevistados e permaneceu igual para 27,0\%. Esses deslocamentos resultaram em aumento nos gastos para $44,3 \%$ dos respondentes. Esses resultados evidenciam que, ao invés de propiciar oportunidades de desenvolvimento econômico para os moradores, a localização do empreendimento contribui para a manutenção ou agravamento da situação já precária de deslocamentos em direção ao local de trabalho na cidade.

\section{Equipamentos públicos e comércio}

O conjunto habitacional Coração de Maria está entre os mais precários empreendimentos do MCMV em Salvador em relação a existência de equipamentos. No raio de 2,5 km do Empreendimento existem duas escolas e duas creches, pertencentes à prefeitura. Entretanto, essas escolas e creches já são deficientes para as comunidades de Nova Esperança. A entrada das 1.800 famílias do Coração de Maria e das 1887 famílias do residencial CEASA ultrapassaria o limite físico desses equipamentos de educação.

Embora tenha sido realizado um diagnóstico da demanda por equipamentos e serviços pela Prefeitura Municipal de Salvador, e prevista a construção de uma escola, uma creche, uma Unidade de Saúde da Família (USF) e um Centro de Referência de Assistência Social (CRAS) na área institucional localizada dentro do empreendimento, o conjunto habitacional Coração de Maria foi entregue aos moradores sem nenhum desses equipamentos.

O fato de o empreendimento ter sido implantado fora da malha urbana, numa área de expansão urbana do município, certamente contribuiu para o desenvolvimento de um comércio incipiente, necessário para atender as demandas cotidianas geradas pelos novos moradores. A existência de uma demanda não atendida por um rol de atividades de comércio, serviços e lazer, levou à construção de barracas nas adjacências do conjunto, de forma improvisada e precária. Conforme indica as Figuras 11,12,13 e 14.

Há muitos casos em que os próprios moradores acabam utilizando espaços do condomínio e/ou de seus imóveis como forma de atuação profissional em serviços e atividades comerciais. Cabe destacar que, por se tratarem de famílias de baixa renda, essas atividades muitas vezes podem corresponder a parcelas significativas da renda da família.
Quadro 4. Tempo de deslocamento casa-trabalho-casa e casa-atividade-casa dos moradores, em valor absoluto e percentual. Fonte: Elaboração própria baseada nos questionários da pesquisa. 

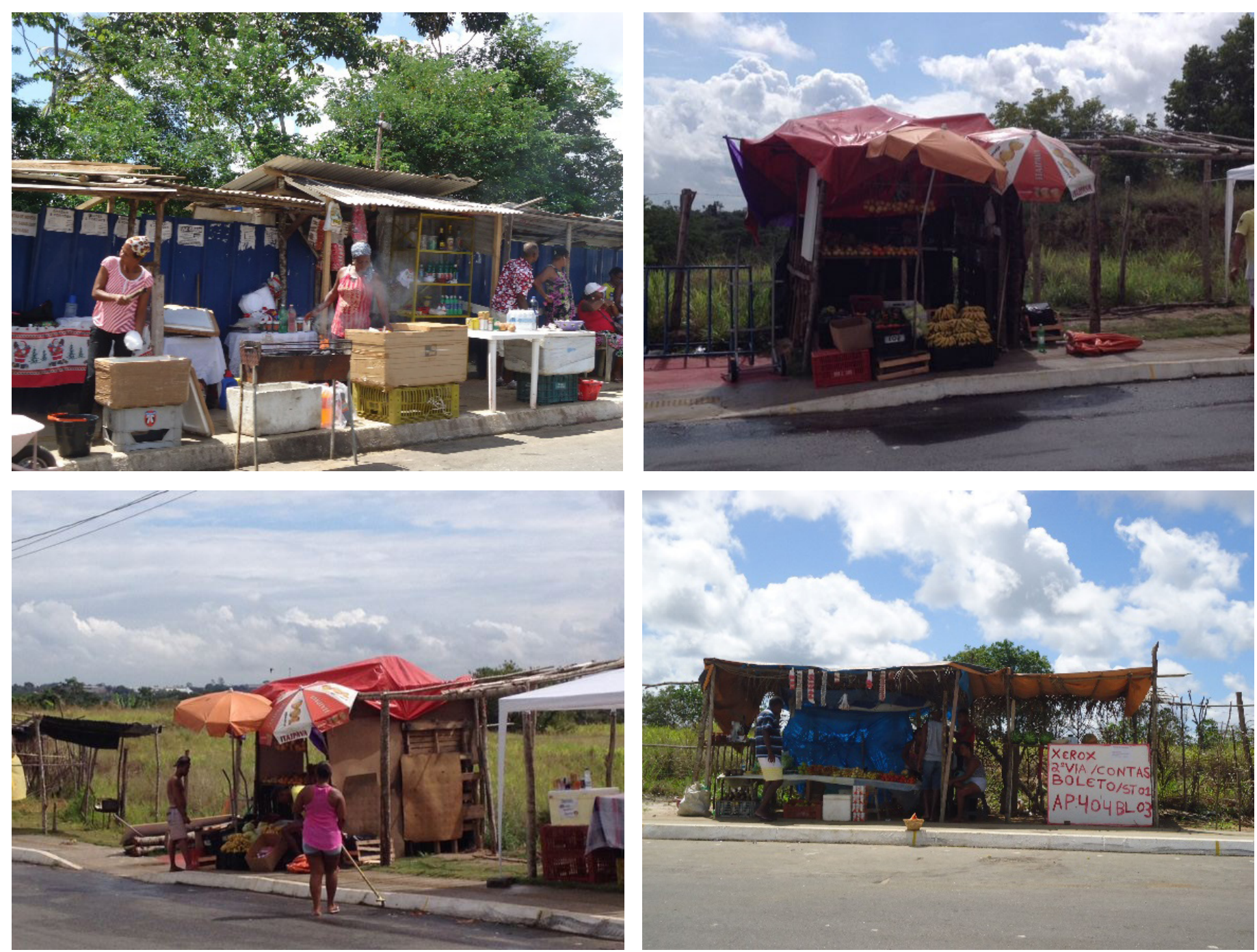

[arriba] Figuras 11 e 12. Comércio informal no empreendimento. Fonte: acervo próprio.

[abajo] Figuras 13 e 14. Barracas informais na via principal dentro do empreendimento. Fonte: acervo próprio.
Considerando-se que historicamente as habitações das famílias de baixa renda nas cidades servem não apenas como lugar de residência, mas também como espaço de trabalho. O modelo de unidade habitacional do MCMV não considera essa multifuncionalidade da moradia, tendo a própria normativa do Fundo de Arrendamento Residencial (FAR) passado a permitir uso misto nas unidades que financia apenas a partir da Portaria 168, em 2013. Naqueles empreendimentos em que não há previsão para esses usos, observa-se o seu surgimento espontâneo em "puxadinhos" improvisados... (Amore et al., 2015).

Em geral, os apartamentos localizados no térreo acabaram se tornando localizações privilegiadas para o desenvolvimento das atividades de comércio de alimentos e bebidas, pois as janelas voltadas para as áreas de circulação internas do condomínio facilitam a interface entre os vendedores e compradores. Mesmo assim, verificou-se a existência de comércio e serviços em todos os andares, anunciados de diversas formas.

Para avaliar a percepção dos moradores entrevistados sobre a oferta de serviços públicos e comerciais no entorno do empreendimento comparado com o local de moradia anterior, foram realizadas perguntas sobre a existência de comércio e serviços no entorno, classificados como serviços públicos básicos (posto de saúde, escola de ensino fundamental, creche e praça), serviços públicos complementares (posto de polícia, hospital, escola de ensino médio, delegacia, delegacia da mulher, Centro 
de Referência de Assistência Social, conselho tutelar, área pública para a prática de esportes, centro cultural, lona cultural, biblioteca pública, internet pública e parque), além de serviços privados/comércio.

O questionário revelou que há uma insatisfação com a questão do acesso a serviços e equipamentos públicos. Dentre os entrevistados, a avaliação predominante é de que, com a mudança da moradia anterior para a atual, houve piora no acesso ao comércio, ao local de trabalho, a equipamentos etc. Quase todas as famílias afirmaram que são obrigadas a se deslocar para outros bairros para fazer compras ou utilizar serviços. Essa necessidade de deslocamentos para suprimento de bens de consumo básicos e cotidianos tem um grande custo para as famílias, não apenas de recursos financeiros, mas de tempo e energia. Os índices revelam que os Serviços Públicos Básicos não são atendidos, como também pioraram com relação à moradia anterior, como mostra o Quadro 5.

\begin{tabular}{|l|l|l|}
\hline Serviços públicos (até 30 minutos a pé) & Moradia atual (\%) & Moradia anterior (\%) \\
\hline UBS/Posto de saúde & 7,6 & 88,1 \\
\hline Escola pública de ensino fundamental & 10,6 & 89,4 \\
\hline Creche & 10,2 & 85,2 \\
\hline Posto de polícia comunitária & 6,4 & 77,1 \\
\hline Praça & 14,4 & 80,9 \\
\hline
\end{tabular}

Os índices dos Serviços Complementares, mesmo sendo o índice com o maior número de variáveis, decresceram vertiginosamente no empreendimento desde a moradia anterior até a moradia atual. A única exceção é em relação a área pública para a prática de esportes que saiu de $73,7 \%$ na moradia anterior, para $91,5 \%$ na moradia atual, con-

Quadro 5. Percepção de oferta de serviços públicos perto (até 30 minutos a pé) da moradia atual e anterior, em percentual Fonte: Elaboração própria baseada nos questionários da pesquisa. forme Quadro 6.

\begin{tabular}{|l|l|l|}
\hline Serviços públicos (na região) & Moradia atual (\%) & Moradia anterior (\%) \\
\hline Hospital/Pronto socorro & 7,6 & 77,1 \\
\hline Escola pública de ensino médio & 10,2 & 86,9 \\
\hline Delegacia & 7,6 & 75,8 \\
\hline Delegacia da mulher & 1,7 & 42,8 \\
\hline CRAS - Centro de Referência da Assistência Social & 8,9 & 59,3 \\
\hline Conselho tutelar & 6,8 & 54,2 \\
\hline Área pública para a prática de esportes & 91,5 & 73,7 \\
\hline Centro cultural & 3,8 & 37,3 \\
\hline Lona cultural & 1,7 & 17,8 \\
\hline Biblioteca pública & 2,5 & 35,2 \\
\hline Acesso público à internet & 4,7 & 25,4 \\
\hline Parque (área verde) & 8,1 & 31,8 \\
\hline
\end{tabular}

Chama a atenção o quanto as condições de acesso ao comércio pioraram, em relação ao domicílio anterior. Os índices dos Serviços Comerciais decresceram em todas as variáveis, como mostra o Quadro 7. Essa percepção resulta de uma ocupação exclusivamente habitacional, sem considerar espaços para comércio e serviços de vizinhança.
Quadro 6. Percepção de oferta de serviços públicos na região da moradia atual e anterior, em percentual Fonte: Elaboração própria baseada nos questionários da pesquisa. 


\begin{tabular}{|l|l|l|}
\hline Serviços comerciais (até $\mathbf{3 0}$ minutos a pé) & Moradia atual (\%) & Moradia anterior (\%) \\
\hline Padaria & 2,5 & 96,6 \\
\hline Mercado ou supermercado & 1,3 & 97,5 \\
\hline Banco & 0,8 & 83,5 \\
\hline Lotérica & 0,4 & 91,1 \\
\hline Feira & 5,5 & 91,1 \\
\hline Farmácia & 0,4 & 95,8 \\
\hline
\end{tabular}

Quadro 7. Percepção de oferta de serviços comerciais perto laté 30 minutos a pé) da moradia atual e anterior, em percentual. Fonte: Elaboração própria baseada nos questionários da pesquisa.

\section{Satisfação e necessidades dos moradores}

Um dos objetivos do questionário aplicado aos responsáveis pelos domicílios foi analisar como eles avaliavam o seu novo local de moradia. Para tal, foi realizada uma série de perguntas (tanto abertas quanto fechadas) relativas ao condomínio como um todo, à unidade habitacional em si, além de possíveis problemas já ocorridos e comparações com os locais anteriores de moradia. As primeiras questões realizadas foram "abertas" para identificar quais elementos seriam acionados de forma espontânea pelos moradores quando questionados sobre os principais pontos positivos e negativos de seu condomínio.

Cabe destacar que entre as categorias mais frequentes entre os entrevistados sobre o que mais gosta no condomínio, "tranquilidade" aparece em um terço das menções, seguida por referências ao apartamento em si, às boas relações com os vizinhos, área verde no entorno, área de lazer, parque infantil, além da infraestrutura do condomínio.

Na pergunta sobre o que menos gosta no condomínio, as categorias mais acionadas foram: "Falta de transporte", com quase um terço do percentual, seguida de "Falta posto de saúde", "Distância", "Falta de segurança", "Falta de escola", "Faltam equipamentos urbanos", "Falta de comércio", "Vizinhança", "Barulho", "Lixo" e "Iluminação pública insuficiente". Cabe destacar a presença das categorias "vizinhança" e "barulho" enquanto referências a problemas de sociabilidade no interior do condomínio, além da categoria "distância" que está associada a queixas em relação à localização do empreendimento em questão, e a categoria "falta de segurança", relacionada a ação de grupos criminosos no interior e no entorno do empreendimento.

Em muitos casos, o desejo de ficar e a satisfação com a nova casa andam lado a lado com a vontade de sair e a insatisfação com uma série de problemas que a mudança para o novo endereço porventura tenha provocado. É importante colocar que 20,3\%, do total de entrevistados no estudo de caso afirmou já ter cogitado a ideia de, em algum momento, mudar-se do seu empreendimento para outro local.

Entre as famílias que pensam em mudar de moradia (20,3\%), 29,1\% apontaram a distância para o local de trabalho como motivação. Não por acaso, pois para $26,2 \%$ dos entrevistados o tempo de deslocamento casa-trabalho é superior a 1 hora, para $22,9 \%$ é superior a 2 horas, e para 11,8\% é superior a 3 horas. Alguns entrevistados desses conjuntos contaram, inclusive, que só vão para seus apartamentos nos fins de semana, para evitar os deslocamentos em dias de trabalho e escola.

$\mathrm{Na}$ sequência dos motivos da vontade de mudar aparecem: Problemas de segurança e violência $(15,2 \%)$, distância família e amigos $(13,9 \%)$, problemas com vizinhança $(12,7 \%)$, falta de condições de pagamento $(3,8 \%)$ e problemas familiares $(2,5 \%)$ (Figura 15). 


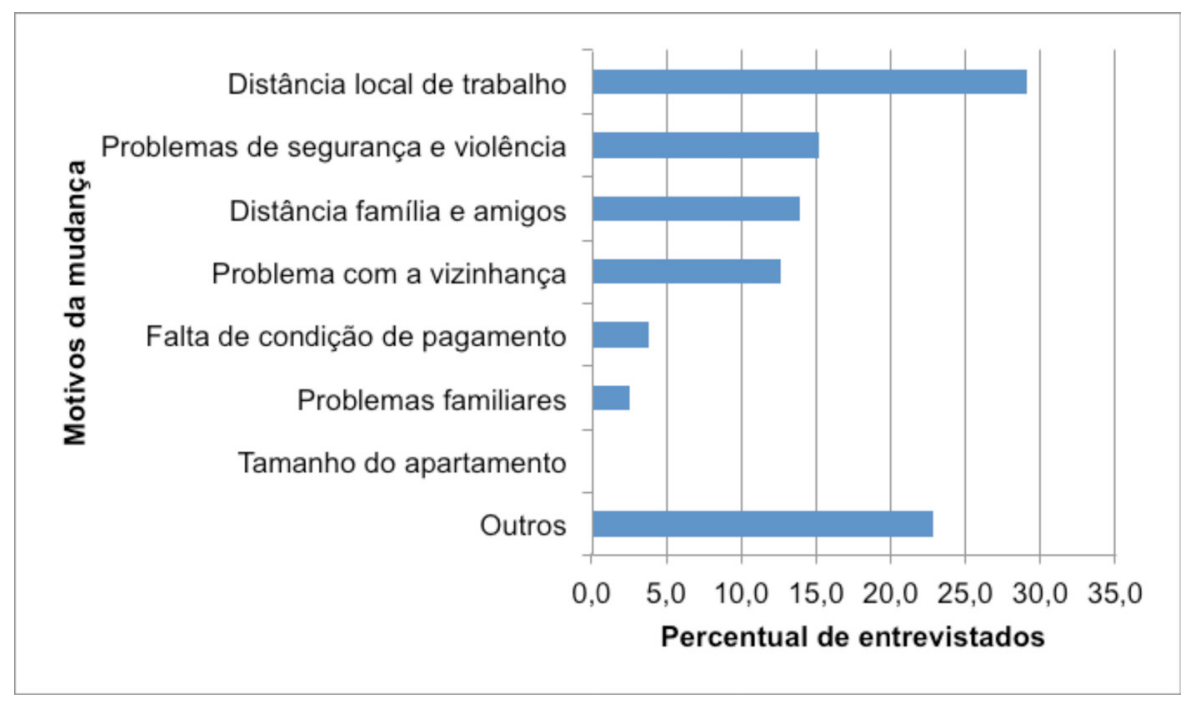

\section{Considerações finais}

A partir das análises desta pesquisa, parece possível afirmar que o problema da habitação, como questão social no Município de Salvador, não se resolve apenas com a construção de unidades habitacionais. Salvador possui um histórico de desigualdade no acesso às redes de infraestrutu$\mathrm{ra}$, transportes, equipamentos e serviços públicos que vem sendo reforçado com a implantação de grandes empreendimentos voltados para a população de baixa renda em áreas de difícil acesso e sem urbanidade. Vale destacar que os desafios de inserção urbana dos empreendimentos do MCMV estão relacionados com o duplo objetivo do programa que, por um lado, visa combater o déficit habitacional, ao mesmo tempo em que estimula a economia através do setor da construção. Na prática este duplo objetivo vem se traduzindo pela priorização da produção de unidades habitacionais em quantidade, enquanto a qualidade da localização e da integração com a cidade ficou relegada ao segundo plano. A produção de condomínios monofuncionais, de grande escala, sem articulação direta com tecidos urbanos consolidados, tende a reforçar esse crescimento urbano desordenado e marcado pelo reforço de novas e antigas precariedades. Tais situações tendem a tornar mais evidente o descompasso entre a acelerada produção de propriedades privadas e as dificuldades e limitações para consolidar situações urbanas adequadas.

Embora as entrevistas realizadas indiquem uma satisfação dos beneficiários do MCMV/FAR por meio da realização do "sonho da casa própria”, esse sentimento se confunde com a insatisfação pela baixa qualidade urbanística que se reflete nas experiências urbanas dos indivíduos e famílias que foram selecionados — "abençoados", "premiados"- As análises realizadas nessa pesquisa indicam que a localização dos empreendimentos no tecido urbano é um elemento crítico que deve ser problematizado no âmbito do processo de implantação do Programa Minha Casa Minha Vida no município de Salvador.

Além disso, analisando o comprometimento da renda familiar com todos os gastos em relação à moradia, os resultados indicam que a forma de posse e o modelo de financiamento adotados pelo programa, provavelmente, não são os mais adequados para as famílias com renda menor e em situações de grande vulnerabilidade e instabilidade, o que torna preocupante a sustentabilidade do programa para este grupo a longo prazo.
Figura 15. Percentual de entrevistados segundo os motivos que levaram a pensar em se mudar do condomínio. Fonte: Elaboração própria baseada nos questionários da pesquisa. 
O histórico das políticas nacionais brasileiras para a habitação mostra como os principais programas nacionais tornaram o problema habitacional - uma obrigação do Estado e um direito- uma questão de mercado (Azevedo y Andrade, 1981), repassando para o setor privado o protagonismo na produção de habitações a serem financiadas. Tal modelo, baseado na lógica de mercado, fez com que as unidades produzidas sempre fossem concebidas como mercadorias, rentáveis aos seus proponentes, o que explica o fato de as políticas sempre terem atingido, predominantemente, a classe média e terem atendido aos interesses do empresariado da construção civil. Essa distorção da política habitacional revela a incompatibilidade da finalidade social da política habitacional com o modo empresarial de produção da moradia. Na impossibilidade de conciliação, os interesses dos empresários influenciaram (e até certo ponto determinaram) os investimentos públicos para habitação e o público para o qual eles seriam direcionados, em detrimento da função social da política habitacional.

Atualmente, no contexto de uma grave crise econômica e política no país, o governo brasileiro anunciou mudanças no Programa MCMV em relação aos valores das faixas de renda com o objetivo de reaquecer o mercado da construção civil. As medidas anunciadas pelo governo mudam as regras para quem está nas faixas de renda 1,5, 2 e 3. Para se enquadrar na Faixa 1,5, a renda total da família passou a ser de até $\mathrm{R} \$$ 2,6 mil. Antes, esse limite era menor, de $\mathbf{R} \$ 2,35$ mil. Para os que se enquadram na Faixa 2, agora é preciso ter uma renda de até $\mathbf{R} \$ 4$ mil. Antes dessas mudanças, o limite era de $\mathrm{R} \$ 3,6$ mil. Na Faixa 3, esse teto de enquadramento subiu de $R \$ 6,5$ mil para $R \$ 9$ mil. O governo tem como meta para 2017, contratar 610 mil unidades habitacionais, sendo 400 mil unidades para as Faixas 2 e 3, 40 mil para a Faixa 1,5 e 170 mil para a Faixa 1 (Ministério das Cidades). E dessa forma, deixa-se de lado mais uma vez o interesse social em detrimento de interesses financeiros. O público-alvo do Programa passa a ser aquelas famílias de renda mensal superior a $R \$ 4000$, ao custo do abandono de sua clientela prioritária: as famílias de mais baixa renda.

Para finalizar, é importante destacar que a questão urbana está intrinsecamente associada, evidentemente, às políticas econômicas. Cidades mais justas só serão possíveis se tivermos no Brasil uma redistribuição efetiva da renda, em uma política macro-econômica inclusiva. Tanto a questão econômica quanto a possibilidade de aplicação de instrumentos urbanísticos democráticos dependem, antes de tudo, de posicionamentos políticos efetivamente em defesa da população excluída e da própria população alvo dessas políticas. 


\section{Referências}

Amore, C., Shimbo, L. y Rufino, M. (2015). Minha casa... e a cidade? Avaliação do programa minha casa minha vida em seis estados brasileiros. Rio de Janeiro: Letra Capital.

Azevedo, S.; Andrade, L.A.G. (1982). Habitação e PoderDa Fundação da Casa Popular ao Banco Nacional de Habitação. Rio de Janeiro: Zahar Editores.

Bolfarine, H. y Bussab, W. (2005). Elementos de amostragem. São Paulo, SP: E. Blücher.

Bahia, Governo do Estado. Secretaria de Desenvolvimento e Urbanismo. Recuperado em 1 de octubre de 2016 de: www.sucom.ba.gov.br.

Brasil, Ministério das Cidades. Recuperado el 1 de octubre de 2016 de: www.cidades.gov.br.

Brasil, República Federativa do. Lei N. ${ }^{\circ} 11977$, de 7 de julho de 2009.

Brasil, Lei N. ${ }^{\circ}$ 10257, de 10 de Julho de 2001. Regulamenta os artigos 182 e 183 da Constituição Federal, estabelece diretrizes gerais da política urbana e dá outras providências.

Caixa Econômica Federal (2016). Apresentação do Balanço do Programa Minha Casa Minha Vida (20092015).

Cardoso, A. y Lago, L. (2015). Avaliação do Programa Minha Casa Minha Vida na Região Metropolitana do Rio de Janeiro: impactos urbanos e sociais. Relatório Final.

Ferreira, J.S.W. (2012). Produzir casas ou construir cidades? Desafios para um novo Brasil Urbano. São Paulo: Fupam.
Gordilho-Souza, A. (2008). Limites do Habitar: Segregação e exclusão na configuração urbana contemporânea de Salvador e perspectivas no final do Século XX. Salvador: EDUFBA.

IBGE. Cidade @-O Brasil município por município. Banco de dados sobre os municípios brasileiros. Recuperado em 1 de octubre de 2016 de: http:/ / www. ibge.net/ cidadesat/default.php.

Rolnik, R. (org.) (2014). Ferramentas para avaliação da inserção urbana dos empreendimentos do MCMV. Relatório da pesquisa. LabCidade FAUUSP. Rede Cidade e Moradia.

Rolnik, R. Guerra dos lugares: a colonização da terra e da moradia na era das finanças. São Paulo: Boitempo.

Salvador (1976). Evolução demográfica de Salvador (19402000). Salvador: UFBA/Centro de Recursos Humanos.

Salvador, Prefeitura Municipal. (1976). PLANDURB-EPUCS: Uma Experiência de Planejamento Urbano. Salvador: OCEPLAN/PLANDURB.

Salvador. Lei n ${ }^{\circ}$ 7400/2008-Plano Diretor de Desenvolvimento Urbano. Salvador, 2008.

Salvador. Lei n ${ }^{\circ}$ 9069/2016-Plano Diretor de Desenvolvimento Urbano. Salvador, 2016.

Santos, E. et al. (orgs.) (2010). O Caminho das Águas em Salvador: Bacias Hidrográficas, Bairros e Fontes. Salvador: CIAGS/UFBA; SEMA.

Andrade Prudente, A. y De Siqueira Leiro, M. (2017). Inserção Urbana no Programa Minha Casa Minha Vida (MCMV): Avaliação do Conjunto Habitacional Coração de Maria no Município de Salvador, Bahia, Brasil. Hábitat y Sociedad, 10, 269-288.

<http://dx.doi.org/10.12795/HabitatySociedad.2017.i10.15> 


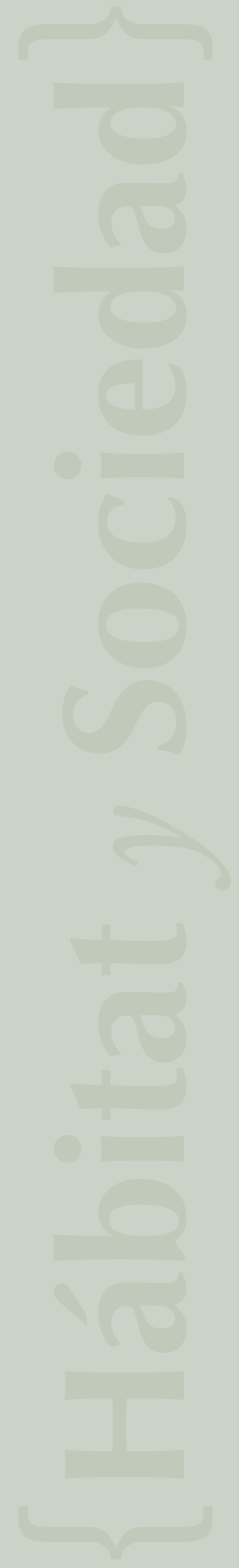

